\title{
Evaluation of land cover changes and secondary ecological succession of typical agroforestry landscapes in Phu Yen Province
}

\author{
Hoi Nguyen Dang ${ }^{1}$, Dung Ngo Trung ${ }^{1^{*}}$
}

\author{
AFILIATIONS \\ 1. Institute of Tropical Ecology, \\ Vietnam-Russian Tropical \\ Centre, № 63, Nguyen Van \\ Huyen Str., Cau Giay District, \\ Hanoi, Vietnam. \\ * Correspondence: \\ ngotrungdung26@gmail.com \\ Tel.: +84936332201
}

RECEIVED 2021-09-01 ACCEPTED 2021-12-07

COPYRIGHT @ 2022 by Forest and Society. This work is licensed under a Creative Commons Attribution 4.0 International License

\begin{abstract}
The study of land cover changes as well as landscape succession has theoretical and practical significance. Determining the characteristics, causes, and trends of the changes and succession of a landscape allows for assessing the natural and human characteristics of the territory. On this basis, appropriate solutions and policies in resource management, socioeconomic development, and environmental protection are available for each locality. Applying and integrating remote sensing data with field investigations and surveys improves the accuracy and reliability of research results. From the establishment of a land cover change map based on land cover map data collected in 2010, 2015, and 2020, variations in the land cover types of Phu Yen Province were observed. In the period 2010-2015, the area of natural forests and grasslands, shrubs, and bare lands decreased rapidly, whereas the covered areas of intentionally planted forests, industrial trees, and crops increased significantly. The secondary ecological succession of the agroforestry landscape of Phu Yen Province in the last 50-60 years occurred under the strong influence of human activities. Under the impact of chemical warfare and policies and farming practices of the local people, several evergreen broad-leaved tropical forest landscape units have undergone four to six stages of succession, with the interweaving of the economic development policy of Phu Yen Province and farming practices of the local people, making the structure and length of each period and succession very different.
\end{abstract}

\section{KEYWORDS}

agroforestry; grasslands and shrubs; human activities; landscape; secondary ecological succession; land cover changes; Phu Yen Province.

\section{INTRODUCTION}

Vegetation is essential because it is the primary means of exchanging substances and energy between the hydrosphere, atmosphere, lithosphere, and biosphere on the Earth's surface (Hu et al., 2010; Piao et al., 2006). Currently, forest ecosystems cover approximately $31 \%$ of the world's floating land, with a total forest area of approximately 4 billion ha (United Nations, 2017). However, under the influence of humans, the forest area and ecosystem are constantly decreasing in terms of area and quality. During the period 1990 and 2015, the annual net deforestation rate at the global scale amounted to $0.13 \%$ (FAO, 2015). Therefore, the management, conservation, and development of forest resources are essential, providing value for agriculture, forestry, tourism, and conservation (Hoi Nguyen Dang et al., 2020; Macdicken, 2015). The protection and sustainable development of landscape and forest ecosystems has thus become an urgent issue of immediate and long-term significance for many countries and territories, including Vietnam (Hien, 2020).

Monitoring and analyzing the distribution of vegetation, forest landscapes, and their composition and changes on spatial and temporal scales based on technical measures are the scientific basis for conservation and development, where the 
application of remote sensing and geographic information system (GIS) technologies is prominent (Bratu, 2019). Remote sensing technology is of great help in monitoring vegetation changes (Hoffer, 1978). Remote sensing and GIS are complementary tools that, when combined, allow for improved mapping, monitoring, and management of forest resources (Franklin, 2001). Remote sensing and GIS have been used since 1932 in Europe and America for forest survey and mapping (Moir, 1932). Meanwhile, GIS provides support to collect, store, retrieve, analyze, and display spatial and attribute data (Oyebade et al., 2012). The application of GIS technology to forest management started in the early 1990s (Ahmad, 2008). Satellite remote sensing data have been widely used to map forests in the tropics, where up-to-date spatial distribution data are unavailable or lacking. The integration of remote sensing data, GPS, and GIS enables natural resource managers and researchers to develop management plans for various agricultural and forest resource management applications (Mani \& A 0, 2018). Currently, remote sensing and GIS applications in forest resource management and protection are deployed in most countries, from Europe, Asia, Australia, and America to Africa (Gopalakrishnan et al., 2019; Hoi Nguyen Dang \& Dung, 2021; Kolosvary \& Corbley, 1998; Linser et al., 2007; Oettel \& Lapin, 2020; Peddi, 2010; Sidiq, 2021; Sonowal, 2020; Strozzi \& Wegmuller, 1998). The results of monitoring and evaluation of forest resources are displayed mainly through forest maps based on GIS software. Forest and landscape maps are the most suitable tools for displaying the content and status of forest vegetation types and their nomenclature proposed by FAO in 2006 (FAO, 2006).

Human activities such as agriculture, deforestation, and construction affect the change of land use patterns, which is the main cause of land use change and class change of vegetation cover, including forest vegetation. These changes are common, increasingly rapid, and at many scales (local, regional, and global), having different impacts on the environment (Yang \& Lan, 1999). Countries in Southeast Asia have different land use policies for plantation development(Crowther et al., 2020; Nambiar, 2021). People's participation in forest management is used in different forms with many terms: community forestry, participatory forestry, village forestry, communitybased forest management, or social forestry (Moeliono et al., 2017). However, the conflict between the community's obligation to protect and benefit from forest values is still weak and the management policy system is not synchronized and not sufficiently strong, which is the cause of high deforestation and degradation (Kane et al., 2018). For example, in Vietnam, payment for forest environmental services has not yet become a stable source of income for the local people. Forest environmental services are limited (Thuy et al., 2020). Therefore, the assessment of land cover changes and the succession of agroforestry landscapes serve as a basis for policymaking and solutions and models for local agroforestry management.

The concept of "succession" was used in the study of vegetation and then used in the study of ecology, the movement of ecosystems (Kuznetsov et al., 2002; Royal Botanic Gardens Victoria, 2016; Wu, 2009). As a mirror reflecting the landscape, vegetation is considered the first sign and the most important component that determines the change and succession of a landscape, especially forest and agricultural landscapes (Gusev, 2012; Hoi Nguyen Dang, Dung, et al., 2019; Hoi Nguyen Dang et al., 2021). Currently, primary ecological succession is found only in newly formed land areas and primeval forests that cover the entire territory of Vietnam. The results of systematically studying the successional characteristics of 
forest landscapes in different regions of Vietnam have recognized the regularity of the secondary ecological succession of landscapes (Hoi Nguyen Dang et al., 2017). Landscape secondary ecological succession shows dissimilarity in both period and phase according to the scale and taxonomic level. On a specific territory, the regularity of ecological succession is regulated by a group of natural factors: topography, climate, soil, and plant nature of the landscape, along with human factors, i.e., policy, farming practices, types of exploitation, and use of the territory. Each group has a significant impact on different landscape taxa. For example, the construction of dams to form reservoirs causes loss of forest landscapes, agricultural landscapes, etc. (disrupting the chain of natural ecological succession) and at the same time directly creates the types and kinds of landscapes of water bodies with new characteristics and a new succession stage (Hoi Nguyen Dang, Huan, et al., 2019). In Vietnam, Nguyen Dang Hoi and colleagues analyzed some secondary ecological succession of Vietnam's tropical monsoon landscape, providing the succession stages of different tropical monsoon landscapes in the Central Region and Highlands (Hoi Nguyen Dang et al., 2016; Hoi N. D. \& Tishkov, 2021). Because abiotic components such as geology, topography, climate, and soil are less likely to be changed, monitoring and assessment of landscape changes and evolution by assessing vegetation cover changes are essential in the landscape.

Phu Yen Province has a forest and forestry land of 276,046 ha, accounting for $55 \%$ of the total natural area, of which the forest area is 218,000 ha. The province's forest cover rate in 2019 reached 44\% (People's Committee of Phu Yen province, 2019). However, similar to many other areas of Vietnam, the area and quality of forests in Phu Yen Province have been fluctuating. Natural forests are reduced in area, size, and quality. The structure of land use purpose conversion in recent years in Phu Yen has also changed, with many districts and households adopting the trend of shifting from land for growing sugarcane, cassava, and even rice to afforestation.

From the above issues, this paper aims to evaluate the land cover change and secondary ecological succession of typical agroforestry landscapes by integrating multitemporal remote sensing data with field survey results and unmanned aerial vehicles. Furthermore, this paper analyzes and identifies the main characteristics and causes (especially human causes) leading to changes in land cover and succession of the landscape of Phu Yen Province over time. The study results contribute to clarifying the regularity and characteristics of land cover change and landscape succession of a province-level territory with complex differentiation topography in Central Vietnam, as well as provide a scientific basis for proposing solutions for management, agroforestry development, and forest protection and development in Phu Yen Province in the current period.

\section{MATERIALS AND METHODS}

\subsection{Study Area}

Phu Yen is a province in the South Central Coast (Figure 1), located to the east of the Truong Son range, with an area of $5,060 \mathrm{~km}^{2}$, of which $70 \%$ is occupied by hills, and a population of over 900,000 people (2019). The population community includes many ethnic groups: Kinh, Ede, Cham, and $\mathrm{Ba} \mathrm{Na}$. The province has 9 district-level administrative units, 110 commune-level administrative units, wards, and townships (People's Committee of Phu Yen province, 2019). It borders Binh Dinh Province to the north, Khanh Hoa Province to the south, Gia Lai and Dak Lak Provinces to the west, 
and the East Sea to the east. Mountainous terrains account for $70 \%$ of the area, and small and narrow plains are distributed along the coast, forming a slope from west to east and strongly dissected.

Phu Yen is located in the tropical monsoon climate, hot and humid, influenced by the sea. The climate is divided into two distinct seasons: the rainy season from September to December and the dry season from January to August. Soil resources are diverse in terms of types. The soil types are distributed over different topographical forms, creating agroforestry ecological subregions suitable for various crops, especially perennial crops in mountainous areas. The river system is relatively evenly distributed throughout the province. Rivers originate from the east

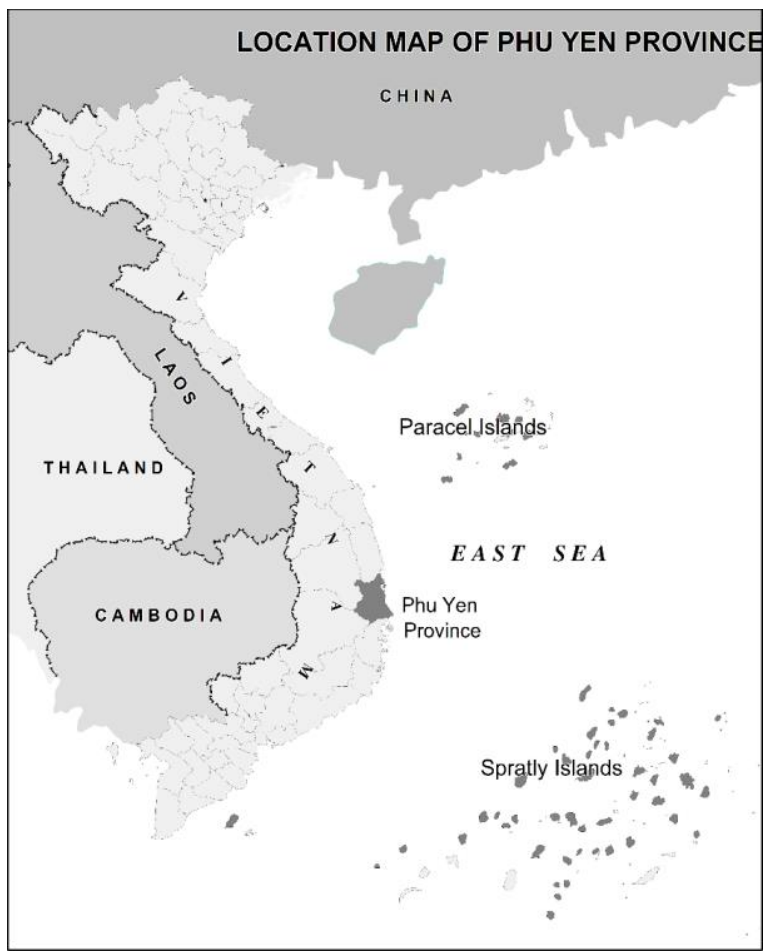

Figure 1. Location of Phu Yen Province in Vietnam of the Truong Son range, flow on hilly terrain in the middle and upstream and narrow plains downstream, and then empty into the sea. Phu Yen has more than 50 large and small rivers, with three main river systems, namely, Ky Lo river, Ba river, and Ban Thach river, with a total basin area of $16,400 \mathrm{~km}^{2}$ and a total flow of 11.8 billion $\mathrm{m}^{3}$, serving as irrigation water for agriculture, industry, hydropower, and people's daily life. The entire province has three main forest types: evergreen broad-leaved closed forest, which is a common forest type in Phu Yen, accounting for $96.5 \%$ of natural forest area; semideciduous semidry forest, accounting for $3.5 \%$ of the province's natural forest area; and the plantation forest, which covers an area of 20,963 ha and approximately 8.4 million scattered trees (equivalent to 4,200 ha), including the main trees such as Acacia indigo, Nacre, Casuarina, Cashew, Dau rot, Black Star, Red Wood, Black Muong, and Giang Huong (Phu Yen Province, 2021).

\subsection{Data and Methods}

\subsubsection{Data}

\section{Current status map of land cover}

To assess changes in some typical agroforestry landscapes of Phu Yen Province, 
we used maps of the current status of land cover in Phu Yen Province for 2010, 2015, and 2020 (Figure 2) within the framework of the topic "Characteristics and Changes of Natural-Anthropogenic Landscapes in Phu Yen Province" of the Vietnam-Russian tropical Center (Vietnam Russian tropical centre, 2021). The current land cover maps in the project are made on the basis of SPOT images in 2010, 2015, and 2020, along with inventory data and forest status announced by Phi Yen Province.
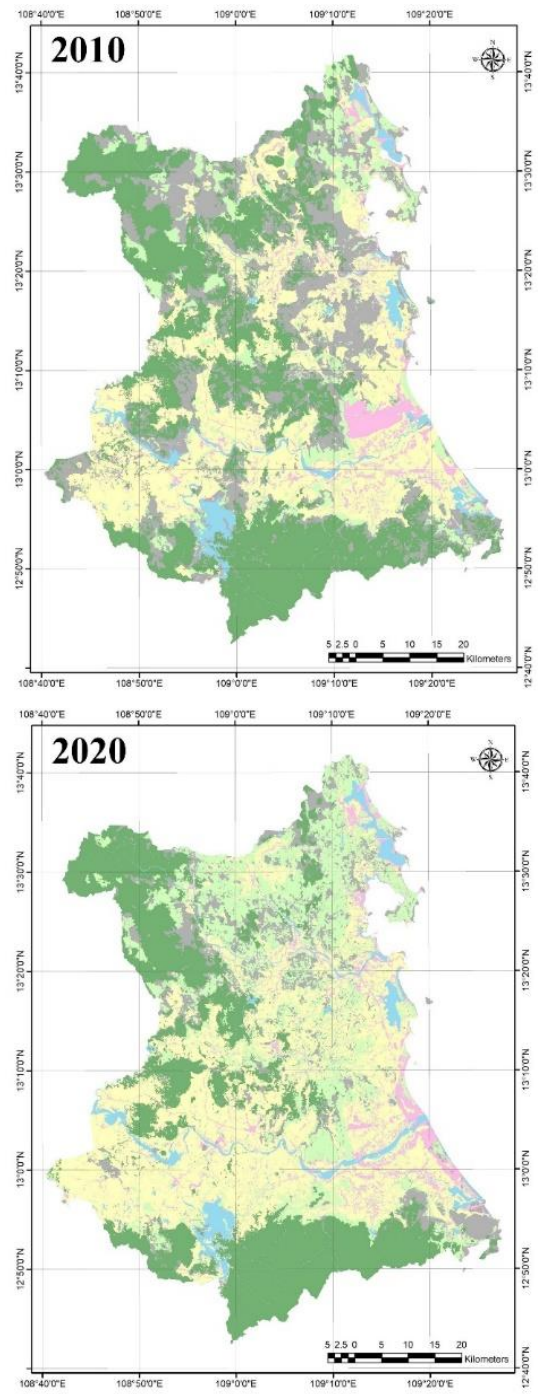

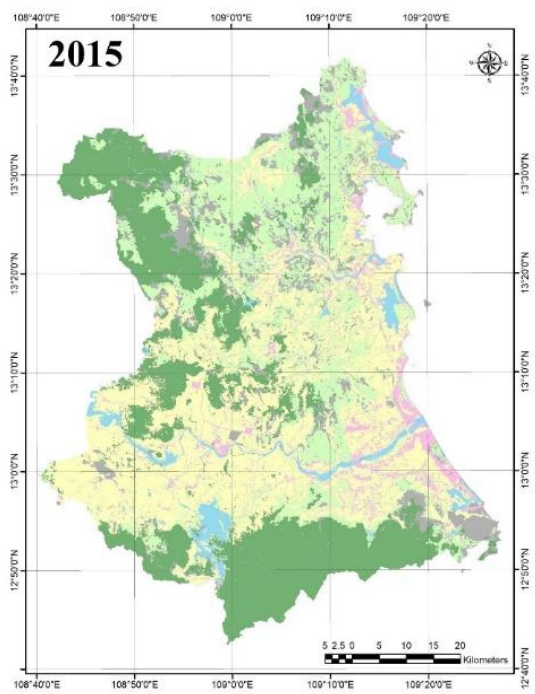

\section{Legend}

\section{Natural forest}

Plantation forest and industrial plants Grasslands, shrubs, and bare land

Annual agricultural crops

Population and vegetation of residential areas

Lakes, rivers, and streams

Figure 2. Land cover maps of Phu Yen Province in 2010, 2015, and 2020, scale $1 / 100.000$ (Vietnam Russian tropical centre, 2021)

\subsubsection{Mapping establishment method}

To establish the land cover change maps for the periods of 2010-2015 and 
2015-2020, first, we determine the current land cover attribute for each contour of the vegetation maps of periods of 2010-2015 and 2015-2020. Accordingly, there are six types of land cover, namely, natural forest, plantation forest and industrial plants, grasslands, shrubs and bare lands, annual agricultural crops, and population and vegetation of residential areas, lakes, rivers, and streams.

Second, we overlay two layers of maps that have homogenized attributes of land cover according to the corresponding years of the vegetation change map based on the Intersect algorithm of ArcGIS 10.8 software. The overlay of maps is modeled, as shown in Figure 3.

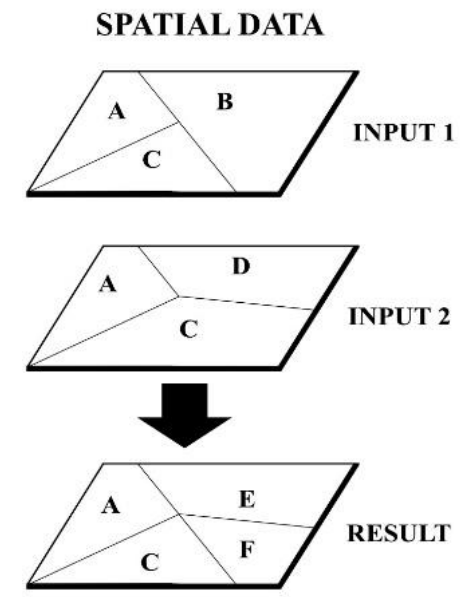

\title{
PROPERTIES DATA
}

\author{
A: Natural forest \\ B: Grasslands, shrubs, bare land \\ $\mathrm{C}$ : Plantation forest and industrial plants \\ D: Annual agriculture crops
}

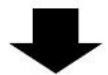

A: Natural forest

C: Plantation forest and industrial plants

E: Grasslands, shrubs, bare land

To Annual agriculture crops

F: Grasslands, shrubs, bare land

To Plantation forest and industrial plants

Figure 3. The process of using GIS to establish land cover change map

Finally, we obtain two resulting maps reflecting the change of vegetation cover in the periods 2010-2015 and 2015-2020.

\subsubsection{Field data collection}

To determine the succession of typical agroforestry landscapes in Phu Yen Province, field surveys were conducted in April 2020 and January 2021 to determine the current structural status (Figure 4). Thirty households, 8 forest rangers, and 10 commune officials from Song Hinh, Son Hoa, and Dong Xuan districts were selected for interviews to determine the timelines of changes in agroforestry landscapes on the map (including the stages of forest exploitation, the stage of conversion of forest land to agricultural land or vice versa, and the transformation of crop structure). The questions asked include the following: What types of crops? The time for planting? How large is the planting area? What are the changes in the farming process according to the timelines from before the liberation date (before 1975) to the present date? What policies on agricultural crop development and forestry and biodiversity conservation in the locality have been applied? For typical agricultural landscapes, the questions focused on clarifying the timelines of changing crops to determine landscape succession. The interviews regarding the characteristics of changes in crop structure and seasonality in the recent decade (2010-2020) were conducted in more detail to serve as a basis to explain the variation of cover types. 
The April 2020 survey focused on the Song Hinh protection forest area, assessing the current status, defining the zoning of tropical forest landscapes, and interviewing local rangers about the timelines for structural change, including the local forestry policy. The following was performed in January 2021: surveying along national highways and provincial roads, approaching typical landscapes in all districts of Phu Yen, checking landscape boundaries, adjusting boundaries, describing structure landscape, especially vegetation structure and topographical features, determining the crop structure, interviewing the local people and officials to collect information on chemical warfare, and changing the structure of agricultural and forestry crops in landscapes.
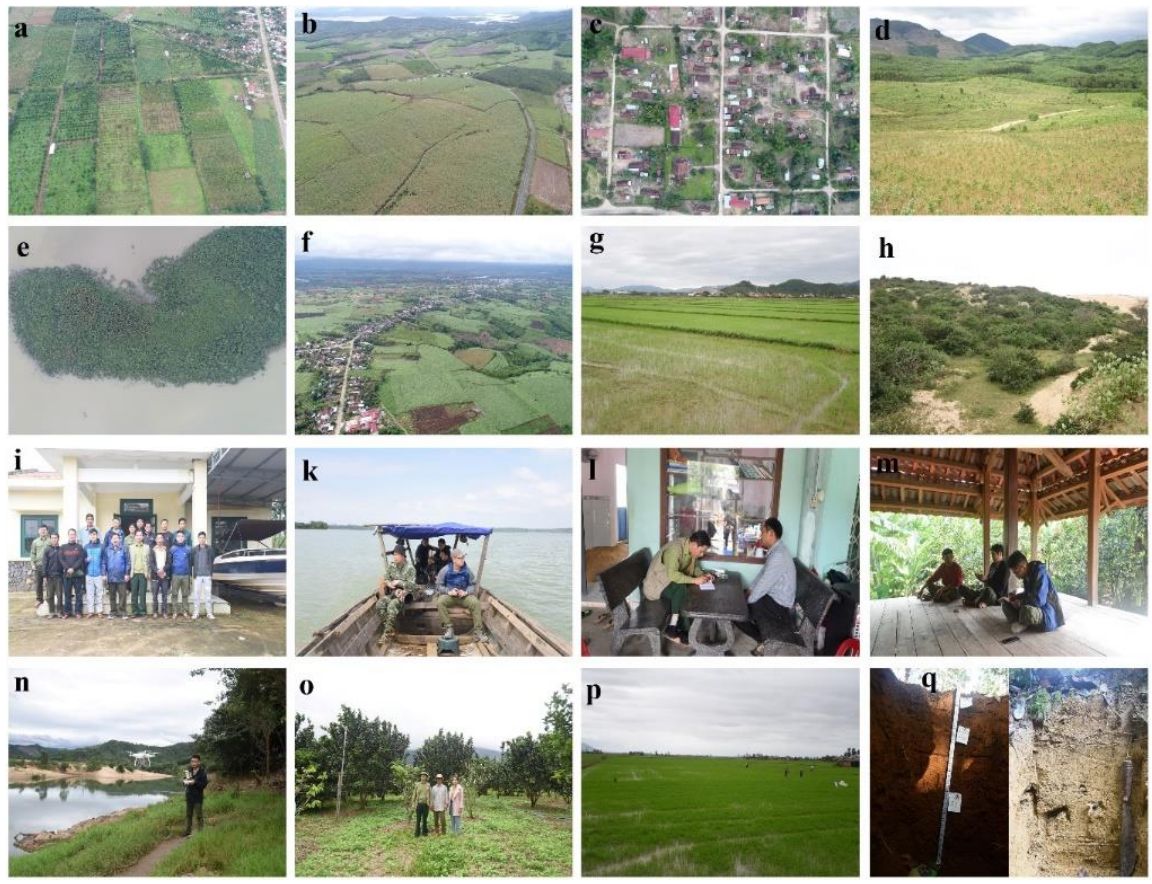

Figure 4. Some pictures of the field survey: a, b, c, f: flying capture of agricultural landscapes and residential areas by drone. d: Acacia plantations. e: Ho Song Hinh acacia plantation. g, p: Landscape of wet rice agriculture. $h$ : Landscape of grasslands and shrubs. i: Survey team and local rangers. k, l, m, n, o: Field survey and interviews with local people. q: Soil profile of rubber plantation and evergreen closed forest in Song Hinh district

\section{RESULTS}

\subsection{Changes in Land Cover Area in the Period 2010-2020}

From 2010 to 2015, the area of natural forest decreased rapidly, with approximately 30,000 ha of forest lost (Table 1 and Figure 5). According to the project report "Planning Special-Use Forests in Phu Yen Province to 2020" in 2013, the area of special-use forests in the entire province has decreased significantly compared to before (Phu Yen People's Committee, 2013). Similarly, the area of grasslands, shrubs, 
and bare land also decreased significantly. Approximately 68,000 ha of grasslands, shrubs, and bare land have been converted for use or changed to the natural state. Meanwhile, the area of plantation forest tended to increase rapidly during this period, with nearly 70,000 ha of planted forests and perennial industrial trees planted. The area of annual agricultural crops has also increased significantly, with approximately 35,000 ha of crops being expanded. During this period, Phu Yen Province promoted the development of agriculture and forestry and mobilized investment capital for afforestation, along with policies to support afforestation by the government of Vietnam. There has been a marked change in the cultivation of agroforestry crops. In addition, the need to increase the area of industrial parks for industrial development purposes of Phu Yen during this period has also increased the area of vegetation of residential areas, with more than 4,500 ha of expanded land area (Table 1 and Figure 5).

Table 1. Changes in the area of land cover types in Phu Yen Province in the period 20102020 (unit: ha)

\begin{tabular}{clrrr}
\hline Item & \multicolumn{1}{c}{ Land cover type } & Area 2010 & \multicolumn{1}{c}{ Area 2015 } & \multicolumn{1}{c}{ Area 2020 } \\
\hline $\mathbf{1}$ & Natural forest & $157,303.16$ & $129,972.28$ & $130,088.14$ \\
$\mathbf{2}$ & Plantation forest and industrial plants & $45,807.76$ & $103,255.80$ & $96,870.27$ \\
$\mathbf{3}$ & Grasslands, shrubs, bare land & $119,144.98$ & $47,122.79$ & $53,977.58$ \\
$\mathbf{4}$ & Vegetation of residential areas & $22,813.60$ & $27,425.19$ & $27,587.30$ \\
$\mathbf{5}$ & Annual agricultural crops & $141,801.27$ & $176,203.22$ & $175,489.33$ \\
$\mathbf{6}$ & Lakes, rivers, and streams & $19,129.23$ & $22,020.72$ & $21,987.38$ \\
\hline & Total & $\mathbf{5 0 6 , 0 0 0 . 0 0}$ & $\mathbf{5 0 6 , 0 0 0 . 0 0}$ & $\mathbf{5 0 6 , 0 0 0 . 0 0}$ \\
\hline
\end{tabular}

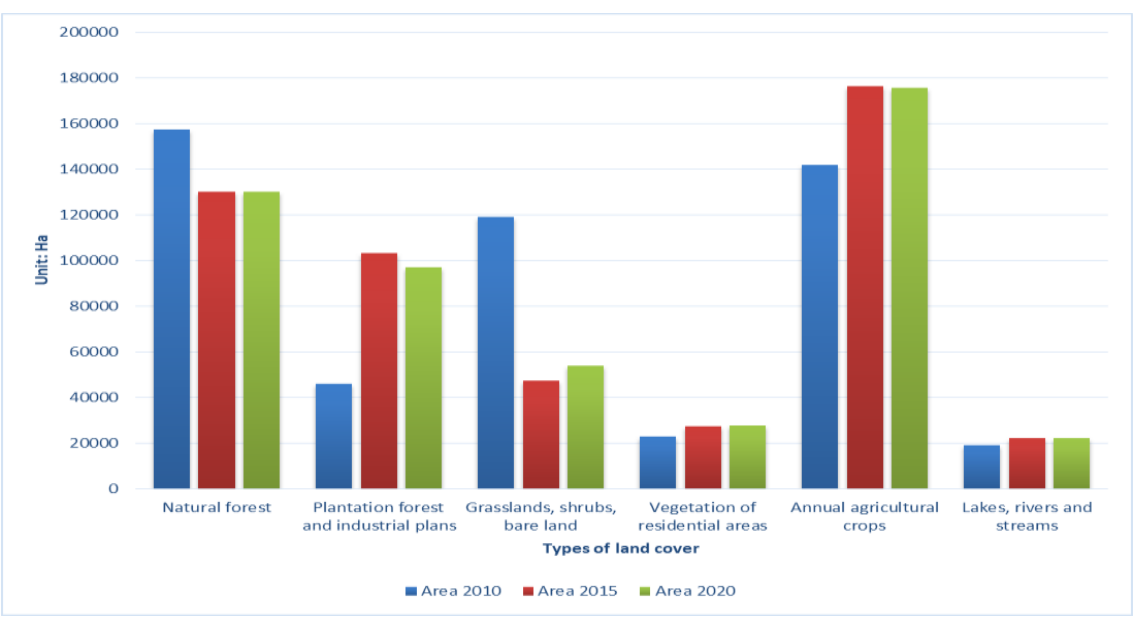

Figure 5. Changes in the area of land cover types in Phu Yen Province in the period 2010-2020 
In the period 2015-2020, the area of land cover types was relatively stable. The strongest fluctuations were observed in the plantation forest and industrial plants, with a decline of 6,500 ha. People do not continue to use some areas of forest land after exploitation but instead leave it empty, so the area of grasslands, shrubs, and bare land tends to increase slightly, with approximately 5,800 ha (Table 1 and Figure 5). Interview results show that, owing to the sharp decline in productivity and value of some perennial industrial crops, especially rubber, people tend to switch from forestry land to agricultural land for annual agricultural crops with less capital and faster capital recovery than forestry crops. However, for some crops such as cassava, after a few years of planting, the land becomes degraded, and people tend to fallow instead of improving soil quality. Therefore, the total area of crops in Phu Yen Province did not fluctuate strongly during this period. From 2015 to 2020, the area of natural forest tended to be significantly more stable than that in the period 2010-2015, when it only increased by approximately 100 ha. Phu Yen Province's natural forest protection policies and forest land use plans for the period 2015-2020 have yielded some results, contributing to the protection and stabilization of the natural forest area.

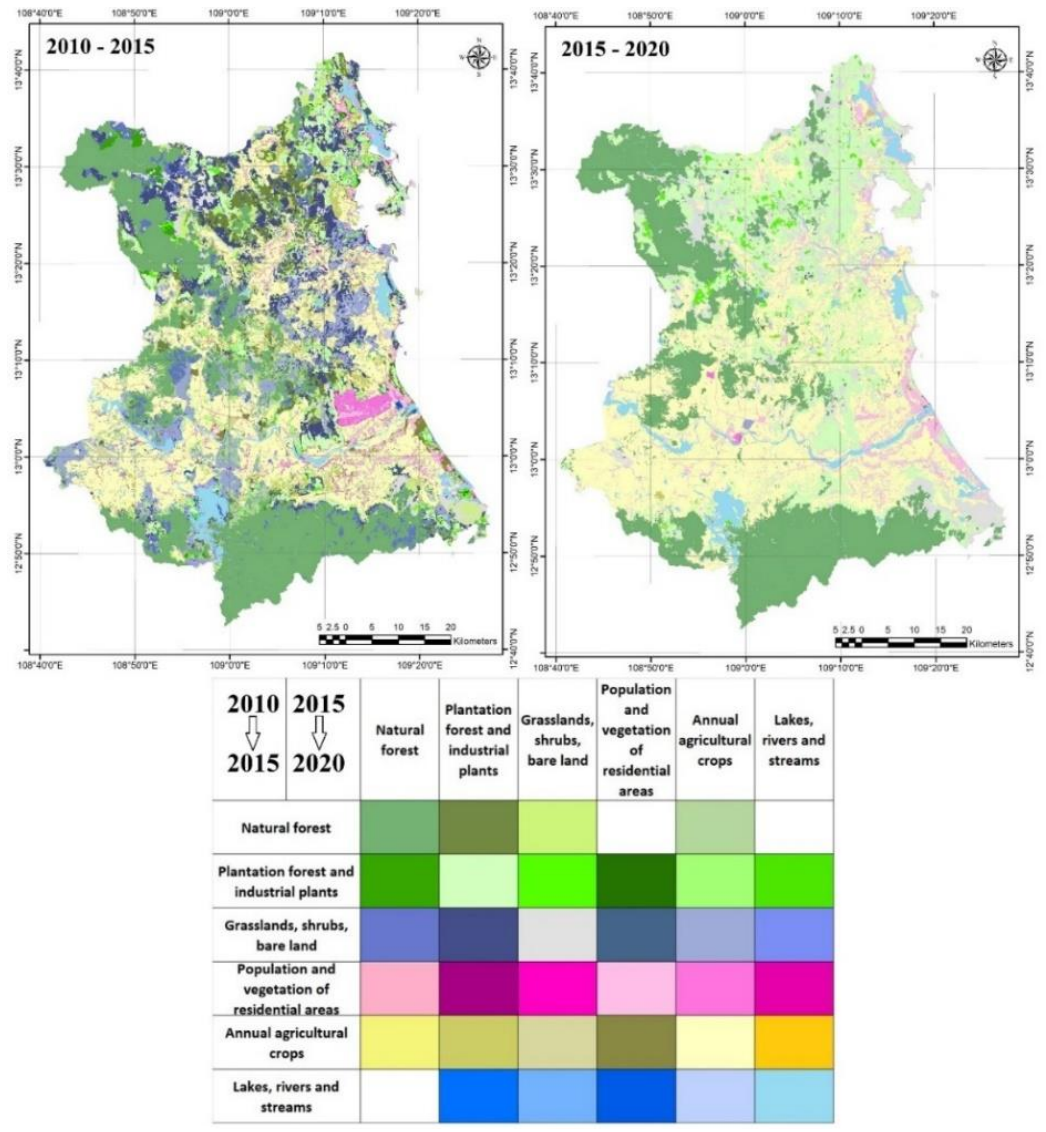

Figure 6. Land cover change maps of Phu Yen Province in the periods of 2010-2015 
and 2015-2020. (From top to bottom: the old mantle has been converted to a new land cover)

Table 2. The matrix of changes in the area of land cover types in Phu Yen Province in the two periods 2010-2015 and 2015-2020 (unit: ha)

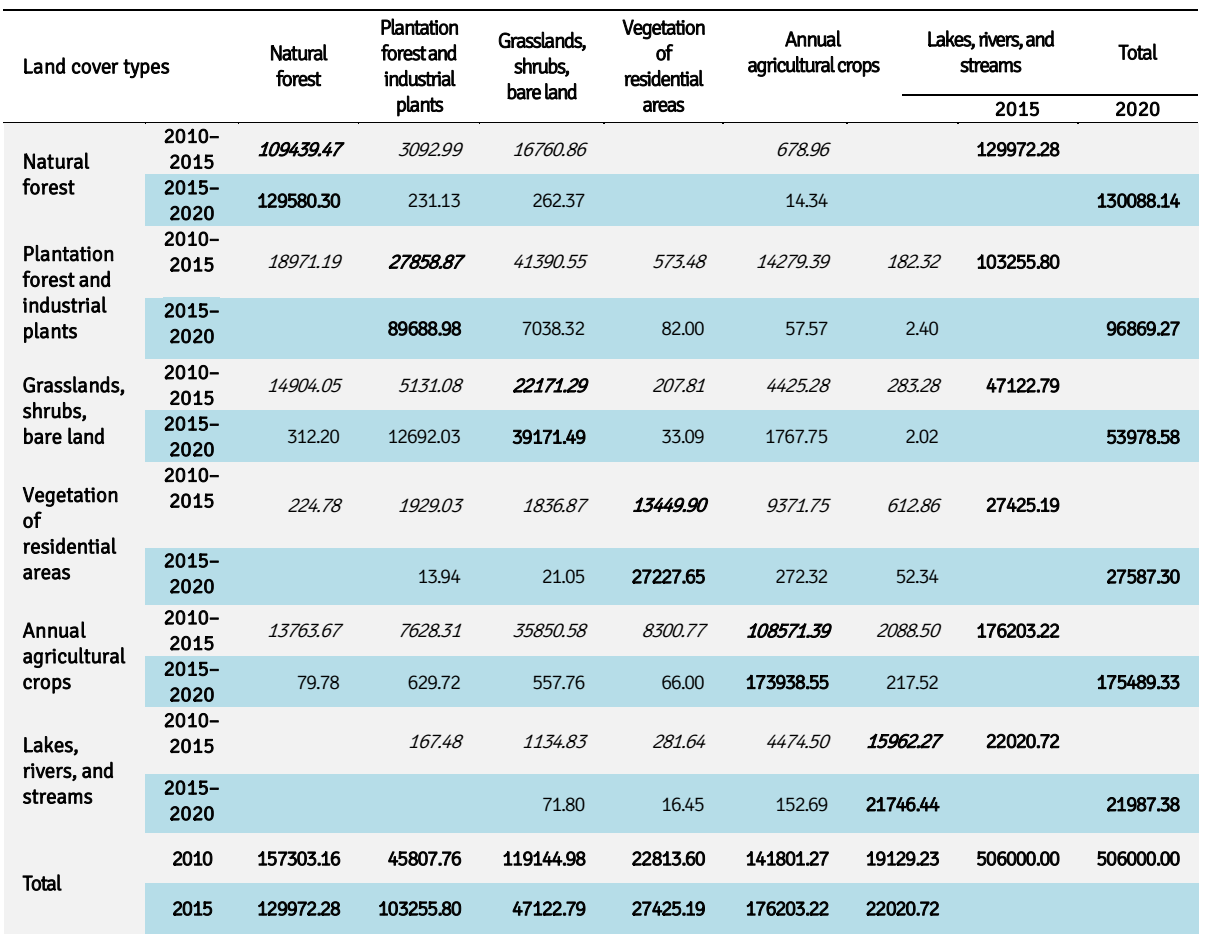

According to Figure 6 and Table 2, the area of natural forest converted to plantation forest and industrial plants was nearly 19,000 ha in the period 2010-2015, with nearly 14,000 ha converted to annual cultural crops and nearly 15,000 ha converted to grasslands, shrubs, and bare lands. This is a particularly severe period of natural forest loss in Phu Yen Province, with approximately 48,000 ha of natural forest exploited or converted for use. However, during this period, approximately 20,000 ha of new natural forest was formed, of which mainly natural recovery from grassland and shrub and bare land landscapes is found. This period also witnessed a large increase in plantation forest and industrial plants, with more than 40,000 ha converted from grasslands, shrubs, and bare land and nearly 15,000 ha converted from annual agricultural crops, concentrated in the northern part of the province. The dramatic change in the cover of grasslands, shrubs, and bare land is also due to the conversion to annual agricultural crops, with a total converted area of more than 35,000 ha. During this period, the vegetation of residential areas' cover pattern changed, as more than 8,300 ha was converted to annual agricultural crops. However, more than 9,300 ha of agricultural land, nearly 4,000 ha of planted forests, industrial trees and grasslands, and bare land have been converted into residential areas and industrial lands. Therefore, the total area of vegetation of residential areas is still 
increasing, mainly in Tuy Hoa city (Figure 6). Fluctuations in water surface area are small, which are concentrated in the Song Hinh Lake area in the southwest of Phu Yen Province.

From 2015 to 2020, based on Figure 6 and Table 2, the stability of coating forms was shown, with small fluctuations in all coating forms. During this period, only plantation forest and industrial plants experienced a decline in size and greater variation. Accordingly, more than 7,000 ha of grasslands, shrubs, and bare lands has been converted. However, more than 12,600 ha of plantations and industrial crops has been converted into grasslands, shrubs, and bare lands. The area of natural forest in this period was very stable when only 231 ha was converted to planted forests and 262 ha to grasslands and bare lands. In contrast, 312 ha of grassland and 80 ha of agricultural land have been restored to natural forest. The total area of agricultural land has decreased slightly, with approximately 2,300 ha converted to other land cover types and 1,500 ha converted. The types of land cover or water surface are stable in the area during this period.

\subsection{The Succession of Typical Agroforestry Landscapes in Phu Yen Province}

Similar to many other areas in Vietnam, the succession of agroforestry landscapes in Phu Yen Province is the ecological succession of human life. Human activities, especially indigenous farming practices and policies in agricultural and forestry development, have become the main factors determining the change and succession of many landscapes, especially the agricultural landscape in the past few decades.

The impacts of natural factors, especially the diverse and continuous impacts of human activities, have significantly influenced the landscapes, forming secondary ecological succession chains under the influence of natural factors, i.e., people in most of the territory of Phu Yen Province. The sequences of secondary succession of transforming the natural forest into plantation forest or agricultural land through different stages are the outstanding succession forms of Phu Yen's agroforestry landscape. Owing to the increasingly strong human impacts on the landscape, with an increasing scale and extent, most landscapes have the characteristics and bold expression of human factors with components and elements of the built, man-made landscape. Depending on the distribution and properties of the zonal or azonal components and elements, the sequence of secondary ecological succession of the landscape occurs in different directions, with the duration of each succession stage varying.

The landscape of Song Hinh district reveals that the succession process is intertwined between natural laws (forest landscape in the core areas of Song Hinh and Krong Trai protected forests) and human laws (agricultural landscape, landscape of population, and landscape of human water bodies in the buffer zone). Here the secondary ecological succession of the landscape occurs because of the postwar period and the farming practices of the local people, especially the Ede ethnic group in different directions. From 1962 to the present date, under the effects of chemical warfare, forest exploitation, deforestation, and shifting cultivation, many landscapes in the region have undergone four to six stages of ecological succession. Secondary species with different vegetation types, from evergreen tropical forests to dominant broad-leaf trees of the Dipterocarpaceae, Magnoliaceae, and Fabaceae through intermediate stages to the present are characterized by planted forests, human-made water bodies (hydroelectric reservoirs), or annual agricultural crops. The research 
results show that the succession chains occur in the following main directions: 1) from being a tropical broad-leaf evergreen forest, it has gone through four intermediate stages to become a dominant planted forest (Figure 7a); 2) from being a tropical broad-leaf evergreen forest, it has gone through three intermediate stages to become a landscape planted with Eucalyptus and Hopea species, dominated by Hopea (Figure $7 b)$; 3) from being a tropical broad-leaf evergreen forest, it has gone through two intermediate stages so that the current landscape alternates between shifting cultivation and annual agricultural crops (Figure 7c).
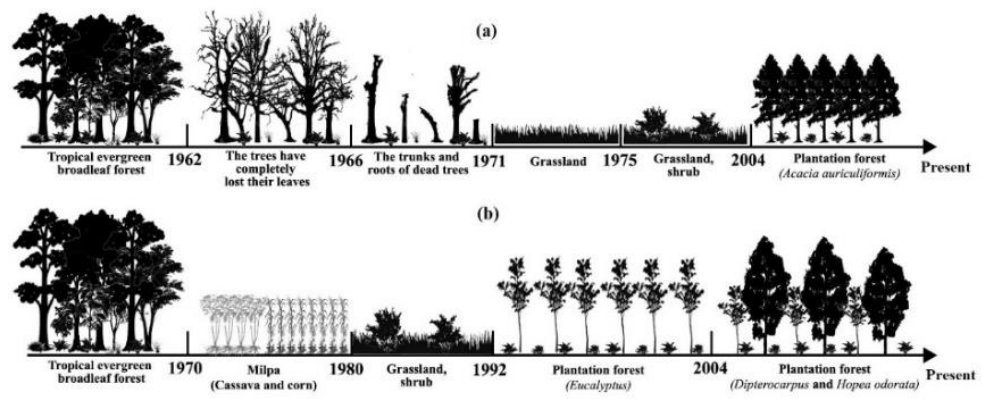

(c)

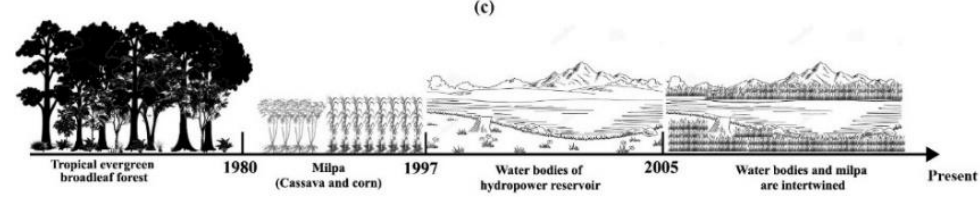

Figure 7. Secondary ecological succession of broad-leaved tropical forest landscape types in Song Hinh district, Phu Yen Province

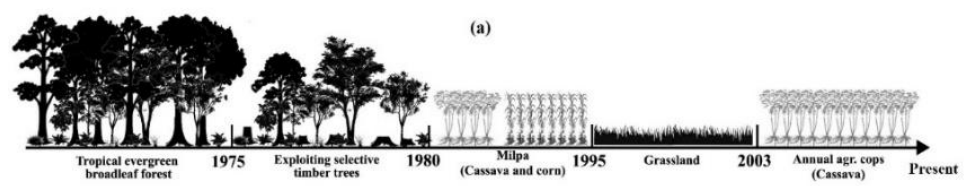

(b)

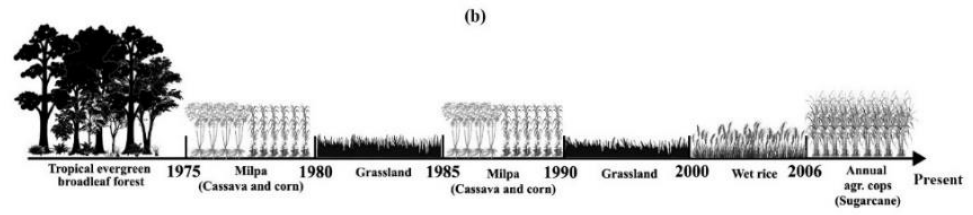

(c)

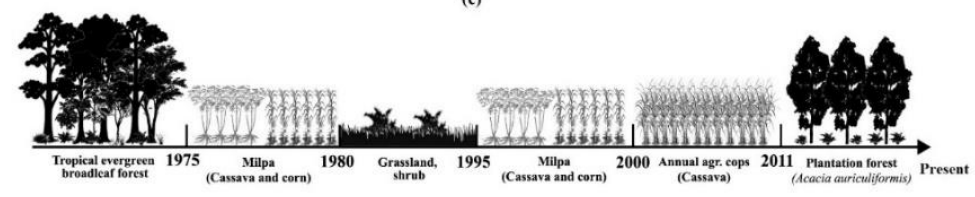

Figure 8. Secondary ecological succession of broad-leaf evergreen tropical forest landscapes in Song Hinh and Dong Xuan districts, Phu Yen Province. 
In the area of Ea Trol commune, Song Hinh district and Phu Mo commune of Dong Xuan district in the North of Phu Yen Province, landscape succession is also strongly differentiated by human activities, mainly after 1975. This is mainly due to agroforestry activities, especially forest exploitation for annual tree-planting activities. In recent years, there has been a conversion to afforestation on a rather large scale. Accordingly, the tropical forest landscapes of evergreen broad-leaf trees after cycles and stages of exploitation become different types of vegetation. In the area north of the hydropower reservoir in Song Hinh commune, Song Hinh district, the landscape of evergreen broadleaved tropical forest after selective exploitation (1975) transformed into a poor forest and was exploited for swidden cultivation. On the old upland field, the grass is grown. By the early 2000s, the landscape was exploited for annual agricultural crops (Figure 8a). In the same type of landscape, in the area of Ea Trol commune, Song Hinh district, since 1975, the landscape of evergreen broad-leaved forest has changed through five intermediate stages to sugar cane crops (Figure 8b). Meanwhile, this type of landscape in Phu Mo commune, Dong Xuan district, in the North of Phu Yen Province, has undergone four intermediate stages after the forest has been thoroughly cleared for farming to present a landscape made up of plantations of Acacia (Figure 8c).

In general, the sequence of secondary ecological succession of agroforestry landscapes in Phu Yen Province is diverse. In particular, the starting point of these sequences are mostly tropical forest landscapes, with high biodiversity and strong human impacts, leading to different stages. Some areas are dominated by nature (regeneration of natural forests after exploitation and formation of grasslands, shrubs, secondary trees), but mainly due to anthropogenic impacts (afforestation, planting industrial crops, agriculture, or development of settlements), creating the diversity of the current landscape.

\section{DISCUSSION}

Integrating remote sensing and field surveying methods allows us to assess and determine the changes of land cover types over different periods and analyze and interpret secondary ecological succession chains through the vegetation cover. In this study, we evaluated the changes in land cover over two periods, namely, 2010-2015 and 2015-2020, and presented typical secondary ecological succession sequences of some agroforestry landscapes in Phu Yen Province.

\subsection{Changes in Land Cover Area in the Period 2010-2020}

In the period 2010-2015, the area of natural forest in Phu Yen Province decreased rapidly, with approximately 30,000 ha of forest lost (Southern Institute of Ecology, 2015). The area of planted forests and industrial plants in the period 20102015 has markedly increased because of the development strategy of production forests of Phu Yen Province in the period 2011-2020 (Phu Yen Provincial People's Committee, 2011). Accordingly, Phu Yen Province has oriented strongly toward developing planted forests, forming a concentrated raw material area on an area of more than 39,000 ha of bare forest land. This is the reason why the area covered with grasslands, shrubs, and bare land during this period has decreased rapidly and is replaced by natural forest restoration and afforestation. This result is also consistent with studies conducted on some provinces in the Central Highlands, Vietnam, during the same period (Hoi et al., 2019; Hoi et al., 2021; Cuong et al., 2019).

In the period 2015-2020, the area of natural forest in Phu Yen Province has been 
relatively stable, with small fluctuations. This is related to the policy of supporting the local people in forestry production and management, with the goal of sustainable forestry development in the province (Phu Yen Provincial People's Committee, 2018). Accordingly, there has been financial support for people and village communities in forest management and afforestation such as support for zoning and regeneration of natural forests and support for afforestation and development of nontimber forest products. This is a very active and timely policy of Phu Yen Province as well as most of the forested provinces in Vietnam, effective in sustainable forestry development and protection and restoration of natural forests (Thuy et al., 2020). In addition, the efforts of forest rangers, along with many strict policies on staff management, including the consolidation of the Sub-Department of Forestry of Vietnam unifying the focal point on forest management, have made the management and protection of forests clearer, more unified, and more effective than before (Phu Yen Provincial People's Committee, 2016). In addition, the strengthening of the local people's capacity for forest protection and development has also been strongly implemented in the period 20152020 not only in Phu Yen Province but also in many other provinces of Vietnam (Ngo et al., 2021).

\subsection{The Succession of Typical Agroforestry Landscapes}

The change of management policies and planning for agricultural and forestry development in Phu Yen Province has created a period of succession of natural forest landscapes as well as agricultural landscapes. From 1962 to 2021 (60 years), the natural-human landscape of Phu Yen Province witnessed many stages of development, under the influence of wars, including chemical warfare, mining policies, industrial-scale forest exploitation, pruning, afforestation, zoning, forest protection, and development of raw material areas such as sugar cane, cassava, acacia, eucalyptus. In addition, during this period, the continuous impacts of the activities of local ethnic communities through deforestation for swidden cultivation, industrial crops, crops, afforestation, rice cultivation, food crops, and other annual agricultural crops increased. This feature is also recorded in Konka Kinh-Konchurang area, Gia Lai Province, and in many areas of Kon Tum Province in the Central Highlands of Vietnam (Hoi et al., 2019; Hoi et al., 2021; Cuong et al., 2019).

In most areas, the landscape is strongly modified, creating different successions from the broad-leaf evergreen tropical forest landscape, most commonly after the war (1975). In some areas affected by the war, herbicides were used by the U.S. in southern Vietnam. In the past 50-60 years, this sequence has undergone four to six stages, showing the typical characteristics of human activities in each of those stages. Compared with those in some other regions, the number of succession stages in Phu Yen is more numerous. For example, in the western region of Kon Tum Province, from the 1970s to the present, under the influence of chemical warfare and other human impacts, landscapes have undergone four stages of secondary ecological succession (Hoi et al, 2019; 2021). In this area, a very special type of secondary ecological succession occurs in the tropical landscape after the impact of chemical warfare. These dynamics are present not only in the Central Highlands of Vietnam but also globally, where there is a pattern of secondary ecological succession of landscapes in monsoon tropical forests with the dominance of Diterocarpaceae under the influence of chemical warfare. The herbicide almost destroyed the natural vegetation and results in the dominance of Dipterocarpaceae. After the spraying of herbicides and napalm bombs (which occurred in this region approximately 50 years ago), grassland 
was established in the landscape and maintained for several decades (Hoi et al., 2021).

The duration and characteristics of each succession stage are very different. Maintenance periods are approximately 4-5 years, but some reach up to 30 years. However, compared to those of many other regions, most of the secondary succession stages of the landscapes of Phu Yen Province are often short and diverse. For example, in the western area of Song Hinh Lake, the landscape of evergreen broad-leaved forest after being sprayed with herbicides lost its leaves completely and remained in this state for approximately 4 years (until 1966) and then became deadwood trees, gradually decaying, falling, and breaking, leaving the trunk and roots intact, and this state remained for approximately 5-6 years (until 1971). Grasslands with the predominance of tropical grass species such as thatch grass, American grass, Waterpipe grass remained for approximately 5 years. In the grassland environment, many shrubs intercropped, including Rhodomyrtus tomentosa, Melastoma candidum, Trema orientalis, Cratoxylum maingayi, Sapium sebiferum (L.), and Roxb, forming grasslands in which shrubs remained for a very long time (approximately 30 years). Since 2004, through the implementation of the forest development policy, many areas have artificially restored some forests, dominated by Acacia indigo and maintained to this day after several new harvests and plantings. Note that the reason why grasslands and shrubs are maintained for so long is due to the frequent impacts of humans, especially the burning and grazing of livestock by the local people.

Some landscapes undergo different stages because of policies (building hydroelectric reservoirs) and spontaneous activities of the local people (swidden cultivation), as seen in Figure 7c, or because of the policy of sugar production, cassava flour production, and spontaneous activities of the local people, as shown in Figures $8 a$ and $8 \mathrm{~b}$. In addition, there are periods when Eucalyptus species are planted with low efficiency and degrade the forest land, so, in Vietnam, there is a policy to replace eucalyptus trees with indigenous species that have economic value, while contributing to biodiversity conservation and better environmental protection. This is the reason why eucalyptus trees are gradually being replaced by species of Oilyaceae shown in Figure $8 b$.

Presently, on the hills and mountains of Phu Yen, different types of landscapes have been replaced by planted forests, with Acacia indigo being the dominant species. Among them, some landscapes have maintained this crop since the 2000s, as seen in Figure $7 \mathrm{a}$, or later grown, as shown in Figure $8 \mathrm{c}$. These are production forest landscapes, where the exploitation cycle of Acacia indigo leaves is 6-7 years. Therefore, during this period, trees are cut down, and the land is improved for new planting. As shown in Figure 7a, Acacia indigo forest has been harvested twice and is now 3 years old. Concerning the landscape shown in Figure 8c, Acacia indigo forest has been harvested once and is now at the age of 4 with good vitality.

Realizing that, the succession features of the agroforestry landscapes of Phu Yen Province are due to the policies of local authorities and spontaneous activities of indigenous people, where policies play a prominent role. In recent years, Phu Yen Province has had many policies for managing, protecting, and restoring forest cover in the entire province. The province has a plan to allocate and lease forests to households, individuals, and communities in the area, where priority is given to synchronous and natural forest areas to districts and communes for management. In particular, the province expanded a large area of timber plantations and granted 
forest certification according to sustainable forest management standards of the Forest Stewardship Council. Phu Yen Province also pursues scientific and technical advances, develops new high-quality forest tree varieties, improves the productivity of planted forests, and provides high incomes to forest growers.

\section{CONCLUSIONS}

The land cover of Phu Yen Province has changed tremendously in the last decade. The establishment of the land cover change map based on the land cover map data in 2010, 2015, and 2020 allows for assessing the change of land cover types over the periods 2010-2015 and 2015-2020. Accordingly, in the period of 2010-2015, the area of natural forests and grasslands, shrubs, and bare lands reduced rapidly and replaced with an increase in the area of planted forest cover and trees and industrial and crops. From 2015 to 2020 , the coating volatility decreased significantly.

The succession of the agroforestry landscape of Phu Yen Province in the last 50 60 years occurred under the influence of natural and human factors, where human activities played the leading role. Under the influence of chemical warfare and local farming policies and practices, most of the tropical forest landscape is typically broadleaf evergreen, undergoing four to six stages of succession.

The formation of succession chains of the agroforestry landscape is due to the interweaving of economic development policies of Phu Yen Province and the local people's farming practices. The combination of these effects determines the duration and characteristics of each stage of succession, which ranges from 4 to 30 years. This serves as a foundation for understanding the perspective of policy proposals in general, and policies on agricultural and forestry development of Phu Yen in particular, in the coming years.

Author contributions: Nguyen Dang Hoi: Established the structure of the article, described the characteristics of the landscape succession, and discussed the research results; Ngo Trung Dung: Correction of data analysis and correction of writing language and main implementation in the establishment of maps.

Competing interests: The authors declare that they have no competing interests.

Acknowledgments: The authors would like to thank Vietnam-Russia Tropical Center, Phu Yen Provincial People's Committee, and Song Hinh Protection Forest Management Board for supporting the authors in the process of data collection and field survey in Phu Yen Province. The authors would also like to thank project E.1.2, task 2, phase 1 "Characteristics and Changes of Natural and Human Landscape in Phu Yen Province" for providing data and financial support for the paper.

\section{References}

Ahmad F. (2008). GIS application for forest management in drylands of Pakistan. Journal of Food, Agriculture and Environment, 6, 388-392.

Bratu I. (2019). Remote Sensing in Forest Management. International conference KNOWLEDGE-BASED ORGANIZATION, 25, 194-198. http://dx.doi.org/10.2478/kbo-2019-0031

Crowther J. O., Zimmer, H., Hanh, L., Quang, T., \& Nichols, J. (2020). Forestry in Vietnam: The potential role for native timber species. Forest Policy and Economics, 116, 102182. http://dx.doi.org/10.1016/j.forpol.2020.102182

FAO. (2006). Global Forest Resources Assessment 2005 (FRA 2005). progress toward 
sustainable forest management, 147.

FAO. (2015). Global Forest Resources Assessment, How Are the World's Forests Changing? Food and Agriculture Organization of the United Nations: Rome, Italy.

Franklin S. (2001). Remote sensing for sustainable forest management.

Gopalakrishnan R., Jha, C., Fararoda, R., Thumaty, K. C., Reddy, S., Singhal, J., . . . Chowdhury, S. (2019). Remote sensing in forest mapping, monitoring and measurement. 18, 27-54.

Gusev A. P. (2012). Successional Processes in the Landscapes of the South-East of Belarus: Analysis of Observations on Permanent Sample Plots. Vesnik VDU, 2(68), 32 - 37.

Hien P. (2020). Forest Management Meeting the Requirements for Sustainable Development in Vietnam. Public Administration Research, 9(2), 15-27. http://dx.doi.org/10.5539/par.v9n2p15

Hoffer R. M. (1978). Biological and physical considerations in applying computeraided analysis techniques to remote sensing. Remote sensing: the quantitative approach, 227-289.

Hoi N. D., Cuong, D. H., Kolesnikov, S. I., Dung, N. T., \& Minnikova, T. V. (2020). Variety of plants and differentiation of forest structure along the height of the mountain range Ngoc Linh, province of Kon Tum, Vietnam. Paper presented at the Scientific Notes of the V.I.Vernadsky Crimean Federal University. Biology. Chemistry. https://cyberleninka.ru/article/n/raznoobrazie-rasteniy-idifferentsiatsiya-struktury-lesa-po-vysote-gornogo-hrebta-ngok-lin-provintsiyakon-tum-vietnam

Hoi N. D., \& Dung, N. T. (2021). Seasonal Dynamics of Tropical Forest Vegetation in Ngoc Linh Nature Reserve, Vietnam Based on UAV Data. Forest and Society, 5(2), 376-389. http://dx.doi.org/10.24259/fs.v5i2.13027

Hoi N. D., Dung, N. T., Cuong, D. H., Kolesnikov, S. I., \& Tishkov, A. A. (2019). Transformation and ecological succession of natural-anthropogenic landscapes in Konkakinh-Konchurang conservation territory, Vietnam. Paper presented at the WORKS OF THE KARADAG SCIENTIFIC STATION NAMED AFTER T.I. VYAZEMSKY - NATURAL RESERVE OF RAS, Federal Research Center "Institute of Biology of the Southern Seas named after A.O. Kovalevsky RAS" (Sevastopol).

Hoi N. D., Huan, N. C., \& Dung, N. T. (2016). The human evolution of the landscape at the Indochina junction in the districts of Ngoc Hoi, Sa Thay and la H'Drai, Kon Tum province. Paper presented at the Proceedings of the Association 9th National Geographic Science Conference, Hanoi.

Hoi N. D., Huan, N. C., \& Dung, N. T. (2019). Secondary ecological succesion of monsoon tropical landscapes in Vietnam: some theoretical and practical issues. Paper presented at the Proceedings of the 11th National Geographic Science Conference, Hue.

Hoi N. D., Huan, N. C., Dung, N. T., Cuong, D. H., \& Ilyich, K. S. (2021). Secondary Ecological Succession of Landscapes in Vietnam along Indochina T-Junction Indian Journal of Ecology, 48(2), 349-357.

Hoi N. D., Kuznetsov, A. N., \& Kuznetsova, S. P. (2017). Some characteristics of secondary succession of tropical monsoon forests in Central Vietnam. Journal of Tropical Science and Technology, 15, 26-35.

Hoi N. D., \& Tishkov, A. A. (2021). Secondary successions and structure of tropical monsoon landscapes in Central Vietnam. Izvestiya RAN. Series Geographic, 
85(1), 1-12.

Hu C., Fu, B.-J., Liu, G.-h., Jin, T., \& Guo, L. (2010). Vegetation patterns influence on soil microbial biomass and functional diversity in a hilly area of the Loess Plateau, China. Journal of Soils and Sediments, 10, 1082-1091. http://dx.doi.org/10.1007/s11368-010-0209-3

Kane S., Dhiaulhaq, A., Sapkota, L. M., \& Gritten, D. (2018). Transforming forest landscape conflicts: the promises and perils of global forest management initiatives such as REDD+. Forest and Society, 2(1), 1-17. http://dx.doi.org/10.24259/fs.v2i1.3203

Kolosvary R., \& Corbley, K. P. (1998). Forest management with GIS. 12, $27-29$.

Kuznetsov A. N., Khoi, S., Luong, P., Borisenko, A., Thinh, N., Bobrov, V., \& Zinoviev, A. (2002). Results of complex zoological-botanical expedition in Cat Loc, Cat Tien National Park.

Linser S., Gallaun, H., \& Schardt, M. (2007). Remote sensing based forest map of Austria and derived environmental indicators.

Macdicken K. (2015). Global Forest Resources Assessment 2015: What, why and how? Forest Ecology and Management, 352. http://dx.doi.org/10.1016/j.foreco.2015.02.006

Mani J. K., \& A O, V. (2018). Remote Sensing and GIS in Agriculture and Forest Resource Monitoring (pp. 377-400).

Moeliono M., Thuy, P. T., Waty Bong, I., Wong, G. Y., \& Brockhaus, M. (2017). Social Forestry - why and for whom? A comparison of policies in Vietnam and Indonesia. Forest and Society, 1(2), 78-97. http://dx.doi.org/10.24259/fs.v1i2.2484

Moir S. (1932). Aerial Forest Mapping. Journal of Forestry, 30, 336-339.

Nambiar S. (2021). Strengthening Vietnam's forestry sectors and rural development: Higher productivity, value, and access to fairer markets are needed to support small forest growers. Trees Forests and People, 3, 100052. http://dx.doi.org/10.1016/j.tfp.2020.100052

Ngo T. T. H., Nguyen, T. P. M., Duong, T. H., \& Ly, T. H. (2021). Forest - Related Culture and Contribution to Sustainable Development in the Northern Mountain Region in Vietnam. Forest and Society, 5(1), 32-47. doi: 10.24259/fs.v5i1.9834

Oettel J., \& Lapin, K. (2020). Linking forest management and biodiversity indicators to strengthen sustainable forest management in Europe. Ecological Indicators, 122. http://dx.doi.org/10.1016/j.ecolind.2020.107275

Oyebade B., Aiyeloja, A. A., \& Aigbe, H. I. (2012). Geographical Information System (GIS) Applications in Forest Resource Assessment and Management.

Peddi A. (2010). Development of Geospatial Decision Support System for Forest Management using Gis and remoteSensing.

People's Committee of Phu Yen province. (2019). Socio-economic report of Phu Yen province in 2019.

Phu Yen People's Committee. (2013). Planning of special-use forests in Phu Yen province to 2020. Phu Yen.

Phu Yen Province. (2021, 21/07/2021). https://phuyen.gov.vn/wps/portal/home/trang-chu/chi-tiet/gioi-thieu/gioithieu-chung.

Phu Yen Provincial People's Committee. (2011). Decision 1686/QD-UBND in 2011 approving the detailed planning on development of production forests to each forest owner area in the period 2011-2020, Phu Yen province. Phu Yen. 
Phu Yen Provincial People's Committee. (2016). Decision No. 1097/QD-UBND on the establishment of the Phu Yen Provincial Forest Protection Department under the Department of Agriculture and Rural Development: Phu Yen.

Phu Yen Provincial People's Committee. (2018). Decision No: 48/2018/QD-UBND: Regulations on support levels for the implementation of the target program for sustainable forestry development in the 2016-2020 period in Phu Yen province. Phu Yen.

Piao S., Fang, J., \& He, J.-S. (2006). Variations in Vegetation Net Primary Production in the Qinghai-Xizang Plateau, China, from 1982 to 1999. Climatic Change, 74, 253-267. http://dx.doi.org/10.1007/s10584-005-6339-8

Royal Botanic Gardens Victoria. (2016). Landscape Succession Strategy Melbourne Gardens Melbourne.

Sidiq A. (2021). Critical Approaches to GIS and Spatial Mapping in Indonesia Forest Management and Conservation. Forest and Society, 5(2), 190-195. http://dx.doi.org/10.24259/fs.v5i2.10921

Sonowal c. (2020). Community Involvement in Forest Management: A Social Analysis of Joint Forest Management in Maharashtra, India. Journal of human ecology (Delhi, India), 72, 148-166. http://dx.doi.org/10.31901/24566608.2020/72.13.3279

Southern Institute of Ecology. (2015). Building biodiversity database in Phu Yen province (phase 1 - forest biodiversity database) (pp. 350). Phu Yen Provincial People's Committee.

Strozzi T., \& Wegmuller, U. (1998). A forest map of a part of Switzerland.

Thuy P. T., Chau, N. H., Chi, D. T. L., Long, H. T., \& Fisher, M. R. (2020). The politics of numbers and additionality governing the national Payment for Forest Environmental Services scheme in Vietnam: A case study from Son La province. Forest and Society, 4(2), 379-404. http://dx.doi.org/10.24259/fs.v4i2.10891

Triskov A. A. (2012). Successions of vegetation of zonal ecosystems: comparative geographical analysis, significance for the conservation and restoration of biodiversity. Izvestia of the Samara Scientific Center of the Russian Academy of Sciences, 14(1), 1387-1390.

United Nations. (2017). The Sustainable Development Goals Report. Available online: https://unstats.un.org/sdgs/files/report/2017/TheSustainableDevelopmentGoal sReport2017.pdf (accessed on 6 February 2020).

Vietnam Russian tropical centre. (2021). Research on the structural and functional organization of tropical forest ecosystems for conservation, restoration and sustainable use.

Wu J. (2009). IV.3 Ecological Dynamics in Fragmented Landscapes (pp. 438-444).

Yang X., \& Lan, R. (1999). Change Detection Based on Remote Sensing Information Model and its Application on Coastal Line of Yellow River Delta. Paper presented at the Proceedings of the 20th Asian Conference on Remote Sensing (ACRS), China. 